\title{
The thorny path linking cellular senescence to organismal aging
}

Christopher K. Patil ${ }^{\mathrm{a}}$, I. Saira Mian ${ }^{\mathrm{a}}$, Judith Campisi ${ }^{\mathrm{a}, \mathrm{b}, *}$

${ }^{a}$ Life Sciences Division, Lawrence Berkeley National Laboratory, 1 Cyclotron Road, Berkeley, CA 94720 USA

${ }^{\mathrm{b}}$ Buck Institute for Age Research, 8001 Redwood Boulevard, Novato, CA 94545 USA

* Telephone: +15104864416

Email: jcampisi@lbl.gov

Keywords:

Cellular senescence; Telomeres; Tumor suppression; Stress resistance. 
Half a century is fast approaching since Hayflick and colleagues formally described the limited ability of normal human cells to proliferate in culture (Hayflick and Moorhead, 1961). This finding -- that normal somatic cells, in contrast to cancer cells, cannot divide indefinitely -- challenged the prevailing idea that cells from mortal multicellular organisms were intrinsically 'immortal' (Carrell, 1912). It also spawned two hypotheses, essential elements of which persist today. The first held that the restricted proliferation of normal cells, now termed cellular senescence, suppresses cancer (Hayflick, 1965; Sager, 1991; Campisi, 2001). The second hypothesis, as explained in the article by Lorenzini et al., suggested that the limited proliferation of cells in culture recapitulated aspects of organismal aging (Hayflick, 1965; Martin, 1993). How well have these hypotheses weathered the ensuing decades?

Before answering this question, we first consider current insights into the causes and consequences of cellular senescence. Like Lorenzini et al., we limit our discussion to mammals. We also focus on fibroblasts, the cell type studied by Lorenzini et al., but consider other types as well. We suggest that replicative capacity in culture is not a straightforward assessment, and that it correlates poorly with both longevity and body mass. We speculate this is due to the malleable and variable nature of replicative capacity, which renders it an indirect metric of qualitative and quantitative differences among cells to undergo senescence, a response that directly alters cellular phenotype and might indirectly alter tissue structure and function.

\section{At least two pathways limit replicative capacity}

Since Hayflick's seminal observations, much progress has been made in understanding why many cells do not undergo proliferation (used here interchangeably with growth) indefinitely in culture. We now understand, at least broadly, that replicative 
capacity is limited by two pathways - one induced by telomere erosion and genotoxic stress, and another induced by stress of an unknown nature. Moreover, other as yet unidentified pathways may also restrict cell division.

\section{The p53 pathway}

For some cells from some species, including the human fibroblasts studied by Hayflick, replicative capacity is limited by the progressive shortening of telomeres (Wright and Shay, 2002). Telomeres, the DNA-protein structures at chromosome ends, shorten with each division because the DNA replication machinery cannot fully replicate 3' termini. In the absence of telomerase, the reverse transcriptase that can add telomeric sequences to chromosome ends, telomeres shorten an average of 50-200 base pairs per cell division. Because mammalian telomeres are many thousand base pairs in length (5-15 kb for humans), most cells divide many times before one or more telomere shortens sufficiently to disrupt the telomeric structure. Disrupted or dysfunctional telomeres resemble irreparably broken DNA; both trigger permanent cell cycle arrest, the hallmark of cellular senescence. This senescence arrest depends on p53 (Rodier et al., 2005), a pleiotropic tumor suppressor that can transactivate or transrepress gene expression, as well as directly facilitate DNA repair and mitochondrially-directed apoptosis (Hofseth et al., 2004). This p53- and telomeredependent growth arrest is known by several names, including telomere-dependent senescence, replicative senescence and telomere-directed aging.

\section{The $\mathrm{p} 16 / \mathrm{pRB}$ pathway}

For other cells, including many human fibroblast strains (as opposed to continuous cell lines), proliferation is spontaneously limited by 'stress', the nature of which is only partly understood. This senescence arrest depends on the p16 tumor 
suppressor, a cyclin-dependent kinase inhibitor that keeps the pRB tumor suppressor/cell cycle regulator in its unphosphorylated growth suppressive form (Ohtani et al., 2004). Culture conditions are not, of course, the tissue environments experienced by cells in vivo. Thus, some culture conditions - for example, atmospheric (hyperphysiologic) oxygen - undoubtedly limit replicative capacity (Sherr and DePinho, 2000; Wright and Shay, 2002; Forsyth et al., 2003; Parrinello et al., 2003; Benanti and Galloway, 2004). It is unlikely, however, that p16-induced senescence is a culture artifact. $\mathrm{p} 16$ is induced in vivo - for example, with age in normal tissues and in response to the stress of chemotherapy in tumors (Zindy et al., 1997; Schmitt et al., 2002;

Krishnamurthy et al., 2004). Thus, culture stress may mimic and/or exaggerate stresses experienced in vivo. Although some cultured human fibroblast strains senesce entirely due to telomere erosion, many form mosaic cultures in which some cells arrest due to telomere dysfunction, while others arrest due to spontaneous p16 induction (Beausejour et al., 2003; Itahana et al., 2003; Herbig et al., 2004). p16-mediated senescence is also known by several names, including premature senescence, SIPS (stress-induced premature senescence) and STASIS (stress or aberrant signaling-induced senescence).

\section{Senescence pathways can intersect and cooperate}

The p53- and p16/pRB-dependent senescence pathways are not completely separable. For example, p53 induces p21, another cyclin-dependent kinase inhibitor, which also inhibits $\mathrm{pRB}$ phosphorylation. Likewise, $\mathrm{pRB}$ can regulate the activity of H/MDM2, which controls p53 stability (Yap et al., 1999). Thus, while one pathway might predominate in limiting replicative capacity under a given set of conditions, the pathways can also cooperate to prevent indefinite cell proliferation, both in culture and in vivo (Lin et al., 1998; Shapiro et al., 1998; Rheinwald et al., 2002; Schmitt et al., 2002; Itahana et al., 2003). 


\section{Species-specific differences -- what does replicative capacity in culture mean?}

Our understanding of mechanisms that limit replicative capacity derives largely from studies of cultured human fibroblasts. How important are these mechanisms for comparable cells from other species?

Telomere-dependent senescence is an important contributor to the limited growth of fibroblasts from humans and non-human primates, but not cells from several rodent (and other mammalian) species (Steinert et al., 2002; Parrinello et al., 2003; Forsyth et al., 2005). In these species, long telomeres and/or expression of telomerase confers an indefinite or greatly extended replicative capacity, once culture conditions are optimized. An illustrative example is fibroblasts from laboratory mice. Laboratory mouse telomeres are longer than human telomeres, and many mouse cells, unlike most human cells, express telomerase (Chadeneau et al., 1995; Prowse and Greider, 1995). Thus, mouse cells should not undergo telomere-dependent senescence. Nonetheless, in standard culture, mouse fibroblasts double only 5-10 times, far less than most human fibroblasts. This limited proliferation is due primarily to the atmospheric oxygen, which causes more DNA damage (resulting in p53-dependent senescence) in mouse, compared to human, cells. Accordingly, the proliferation of mouse cells is enormously extended by simply reducing oxygen to physiologic levels (Parrinello et al., 2003). Thus, human and mouse cells differ qualitatively (dependence on telomere erosion) and quantitatively (sensitivity to oxidative damage) in their propensity to senesce in culture.

What, then, is the replicative capacity of mouse fibroblasts? Clearly, the answer depends on culture conditions. The same is true for human fibroblasts. Although less oxygen-sensitive than mouse cells, human cells generally proliferate longer when cultured in physiological oxygen (Balin et al., 1977; Packer and Fuehr, 1977; Saito et al., 
1995; Balin et al., 2002; Itahana et al., 2003). Likewise, hormones and nutrients can extend their replicative capacity (Forsyth et al., 2003; Mawal-Dewan et al., 2003). Moreover, there is great variability among fibroblast strains from different humans, even when matched for tissue of origin and donor age (Martin et al., 1970; Schneider and Mitsui, 1976; Dimri et al., 1995; Cristofalo et al., 1998) (e.g., some strains undergo <20 doublings, whereas others undergo $>80$ ). All this is to say that proliferation in culture is extremely plastic and variable, even for a single cell type such as fibroblasts. Thus, the distribution of doubling times for cell cultures obtained from different individuals or organisms is likely to be non-normal.

\section{Cell type-specific differences -- what does replicative capacity in culture mean?}

Fibroblasts are, of course, one of many proliferative cell types that comprise complex organisms such as mammals. Is the replicative capacity of fibroblasts similar to that of other cells cultured from the same organism? Would, for example, an adult human with highly proliferative dermal fibroblasts also have highly proliferative $\mathrm{T}$ cells, mammary epithelial cells, aortic endothelial cells, capillary endothelial cells, and fibroblasts from tissues other than skin? After all, while fibroblasts provide crucial structural and informational support for epithelial and other tissues, they are not the stem or progenitor cells that allow renewable tissues to regenerate and repair. These are important questions, but obtaining answers is far from trivial. Should a single culture condition be used, or should conditions be optimized for each cell type -- or each species? And what is optimal? For example, p16 induction can limit the proliferation of human epithelial cells in standard culture and in vivo (Reznikoff et al., 1996; Brenner et al., 1998; Erickson et al., 1998; Dickson et al., 2000; Rheinwald et al., 2002; Holst et al., 2003; Sasaki et al., 2005). Yet it is possible to bypass p16-dependent, but not telomeredependent, senescence by modifying culture conditions (Ramirez et al., 2001). Clearly, 
the modified conditions more accurately report replicative capacity, but which condition more accurately reflects the behavior of cells in vivo? Thus, again, replicative capacity in culture is malleable, and, additionally, may vary with cell type.

\section{Does cellular senescence, or restricted replicative capacity, suppress cancer?}

Given this plasticity and variability, what then is the biological significance of the limited proliferative capacity of cells in culture? Several lines of fairly strong evidence support the idea that cellular senescence suppresses cancer. First, it is now clear that the growth arrested senescent phenotype acquired by cells at the end of their replicative life span can be induced by a variety of stimuli. In addition to dysfunctional telomeres, these stimuli include severe or irreparable DNA damage, oxidative stress, certain oncogenes (particularly those that deliver strong mitogenic signals), and agents that alter chromatin structure (Campisi, 2005). All these stimuli are potentially oncogenic, supporting the idea that the response evolved to prevent the growth of cells at risk for neoplastic transformation. Second, as noted above, the senescence arrest is controlled by $p 53$ and p16/pRB, which lie at the heart of two powerful tumor suppressor pathways. Mutations in these pathways are required in order for cells to continue proliferating in the face of senescence-inducing signals. Moreover, virtually all cancer cells harbor mutations in either the p53 or p16/pRB pathway, or both. Third, mouse models harboring mutations that render cells refractory to cellular senescence are invariably cancer prone. Finally, recent findings indicate that the malignant progression of cells with potentially oncogenic mutations is suppressed by the senescence response, and that this suppression occurs in both mice and humans in vivo (Braig et al., 2005; Chen et al., 2005; Collado et al., 2005; Michaloglou et al., 2005). Thus, the early hypothesis that the restricted proliferative capacity of normal cells suppresses tumorigenesis is on fairly solid ground. 


\section{Does replicative capacity in culture reflect aging? The historic perspective.}

What of the hypothesis that the limited proliferation of cells in culture recapitulates aspects of organismal aging? Early support for this hypothesis came from two types of studies, one indicating that replicative capacity in culture correlates inversely with donor age, and another indicating that replicative capacity in culture correlates directly with species-specific longevity. It is certainly true that regenerative and repair capacity declines with age. However, as discussed by Lorenzini et al., early conclusions that the replicative capacity of cultured human fibroblasts declines with age (Martin et al., 1970; Schneider and Mitsui, 1976) have been questioned (Cristofalo et al., 1998), and in any case, as noted above, there is substantial individual-to-individual variability in the replicative capacities of fibroblast cultures isolated from similarly aged donors. Moreover, Lorenzini et al. now question the other early conclusion, namely that replicative capacity of fibroblasts cultures correlates with species longevity.

\section{Does replicative capacity in culture correlate with species-specific longevity?}

As Lorenzini et al. point out, this conclusion relies heavily on a single study (Rohme, 1981), which did not control for the developmental status of the donor cultures and contained some questionable longevity data. They therefore reassessed the relationship between replicative capacity in culture and species longevity using 59 fibroblast cultures from 11 adult mammals. They used for these studies a single standard culture regimen, which, from the replicative capacity of the mouse fibroblasts tested, likely included atmospheric oxygen. They conclude there is little correlation between the proliferative potential of fibroblasts cultured from adult mammals and species-specific (maximum) longevity, and that any residual correlation is best explained by the relationship between both these variables and body mass. Perhaps this 
conclusion should not be surprising, given how plastic and variable replicative capacity can be and the limits of attempting to draw conclusions about an intact organism from the properties of a single cell type in culture. Also given these considerations, perhaps we should have been more skeptical about the early conclusions drawn from the Rohme study! The better-controlled studies of Lorenzini et al. are more consistent with what is now known about mechanisms that control the senescence response and the behavior of cells in culture.

\section{Does replicative capacity in culture correlate with species-specific body mass?}

In an interesting turn, Lorenzini et al. test the idea that fibroblast replicative capacity is better correlated with species-specific body mass than maximum longevity. The underlying premise is that large mammals have more cells than small mammals, yet all mammals originate from a single cell (the fertilized ovum). Thus, cells from large mammals are likely to have an intrinsically greater capacity for proliferation than cells from smaller mammals. As pointed out by Lorenzini et al., body mass generally correlates with longevity in mammals, and failure to consider this correlation can confound simple correlations between longevity and traits such as cellular replicative capacity in culture (Speakman, 2005). Is there a correlation between replicative capacity and body mass?

For small mammals, ranging in size from 22-520 g (mouse, rat, bat, naked mole rat, squirrel), the answer no - even a cursory analysis of the data shows that the correlation is insignificant. For large mammals, ranging in size from 4-725 kg (cat, dog, human, gorilla, cow), the answer is uncertain. Uncertainties in drawing firm conclusions from the large mammal data set stem from statistical considerations - small cohort sizes; small number of species in this group (one of which - gorilla - is represented by a 
single culture from a single donor); failure to consider (or provide) variance in body mass; and the non-normal distribution of biometric data across species, which violates one assumption of the Pearson correlation (this is partially ameliorated by a logarithmic transformation of the data, which reduces non-normal skewing but also reduces statistical power). Uncertainties also stem from the biological considerations raised above -- caveats regarding the plasticity and variability of replicative capacity in culture, and limits of drawing conclusions about organisms from the behavior of a single cell type in culture. It should also be noted that the expression of telomerase by early embryos obviates the need to invoke differences in proliferative potential among somatic cells. Much of the cell replication that results in intact organisms occurs in utero, when cell division in developing embryos is not limited by telomere erosion or $\mathrm{p} 16$-induced senescence (Prowse and Greider, 1995; Wright et al., 1996; Zindy et al., 1997).

\section{Does replicative capacity in culture reflect aging? Current perspective.}

Is there any relationship between longevity and replicative capacity in culture? From most of the data that have attempted to answer this question directly, the answer appears to be no. We suggest, however, that, more in accordance with the hypothesis as initially conceived, we should perhaps phrase the question differently - is there a relationship between the aging process and the senescence of cells in culture? We further suggest that the answer to this question is - maybe.

First, replicative capacity in culture, despite its malleability, is an indirect gauge of cellular sensitivity to stress. Aside from the oxidative stress caused by culture in atmospheric oxygen, we know very little about what other stresses are imposed by culture conditions. Because stress resistance correlates strongly with longevity (Johnson et al., 2001; Lithgow and Walker, 2002), it will be important to develop more 
physiological culture systems in which age-related changes in cells and tissues can be studied more directly. In addition, as discussed above, cell replication is only one of many stimuli that can cause the permanent arrest of proliferation that is the hallmark of cellular senescence.

Second, the senescence-associated growth arrest is accompanied by striking changes in cellular phenotype. For some cell types, including fibroblasts, these changes include resistance to apoptotic cell death and the secretion of biologically active molecules such as matrix metalloproteinases, inflammatory cytokines and growth factors (Campisi, 2005). These secreted molecules can promote the proliferation and neoplastic transformation of preneoplastic epithelial cells in stromal-epithelial co-cultures and in mice (Krtolica et al., 2001). They can also disrupt the function of normal tissue structures (Parrinello et al., 2005). Thus, relatively few senescent cells can, at least in principle, have far-ranging effects within tissues. We speculate that the gradual accumulation of senescent cells with age may at least partly explain the decline in tissue structure and function that is a hallmark of aging. If this hypothesis is correct, then it may be more important -- and more informative about age-related processes -- to understand age- and species-specific differences in whether cultured cells undergo senescence in response to diverse stimuli. Further, the importance of the senescence response lies not in the trajectory with which they undergo proliferative exhaustion, but what cells do once they have become senescent.

Balin, A.K., Fisher, A.J., Anzelone, M., Leong, I. and Allen, R.G., 2002. Effects of establishing cell cultures and cell culture conditions on the proliferative life span of human fibroblasts isolated from different tissues and donors of different ages. Exp. Cell Res. 274, 275-287. 
Balin, A.K., Goodman, D.B., Rasmussen, H. and Cristofalo, V.J., 1977. The effect of oxygen and vitamin $E$ on the lifespan of human diploid cells in vitro. J. Cell Biol. 74, 58-67.

Beausejour, C.M., Krtolica, A., Galimi, F., Narita, M., Lowe, S.W., Yaswen, P. and Campisi, J., 2003. Reversal of human cellular senescence: roles of the p53 and p16 pathways. EMBO J. 22, 4212-4222.

Benanti, J.A. and Galloway, D.A., 2004. Normal human fibroblasts are resistant to RASinduced senescence. Mol. Cell. Biol. 24, 2842-2852.

Braig, M., Lee, S., Loddenkemper, C., Rudolph, C., Peters, A.H., Schlegelberger, B., Stein, H., Dorken, B., Jenuwein, T. and Schmitt, C.A., 2005. The Suv39h1 histone methyltransferase cancels Ras-initiated lymphomagenesis by mediating cellular senescence. Nature 436, 660-665.

Brenner, A.J., Stampfer, M.R. and Aldaz, C.M., 1998. Increased p16 expression with first senescence arrest in human mammary epithelial cells and extended growth capacity with p16 inactivation. Oncogene 17, 199-205.

Campisi, J., 2001. Cellular senescence as a tumor-suppressor mechanism. Trends Cell Biol. 11, 27-31.

Campisi, J., 2005. Senescent cells, tumor suppression and organismal aging: Good citizens, bad neighbors. Cell 120, 1-10.

Carrell, A., 1912. On the permanent life of tissues outside of the organism. J. Exp. Med. $15,516-528$.

Chadeneau, C., Siegel, P., Harley, C.B., Muller, W.J. and Bacchetti, S., 1995. Telomerase activity in normal and malignant murine tissues. Oncogene 11, 893898.

Chen, Z., Trotman, L.C., Shaffer, D., Lin, H., Dotan, Z.A., Niki, M., Koutcher, J.A., Scher, H.I., Ludwig, T., Gerald, W., Cordon-Cardo, C. and Pandolfi, P.P., 2005. Critical role of p53 dependent cellular senescence in suppression of Pten deficient tumourigenesis. Nature 436, 725-730.

Collado, M., Gil, J., Efeyan, A., Guerra, C., J, S.A., Barradas, M., Benguria, A., Zaballos, A., Flores, J.M., Barbacid, M., Beach, D. and Serrano, M., 2005. Identification of senescent cells in premalignant tumours. Nature 436, 642.

Cristofalo, V.J., Allen, R.G., Pignolo, R.J., Martin, B.G. and Beck, J.C., 1998. Relationship between donor age and the replicative life span of human cells in culture: a reevaluation. Proc. Natl. Acad. Sci. USA 95, 10614-10619.

Dickson, M.A., Hahn, W.C., Ino, Y., Ronfard, V., Wu, J.Y., Weinberg, R.A., Louis, D.N., Li, F.P. and Rheinwald, J.G., 2000. Human keratinocytes that express hTERT and also bypass a p16(INK4a)-enforced mechanism that limits life span become immortal yet retain normal growth and differentiation characteristics. Mol. Cell. Biol. 20, 1436-1447.

Dimri, G.P., Lee, X., Basile, G., Acosta, M., Scott, G., Roskelley, C., Medrano, E.E., Linskens, M., Rubelj, I., Pereira-Smith, O.M., Peacocke, M. and Campisi, J., 1995. A novel biomarker identifies senescent human cells in culture and in aging skin in vivo. Proc. Natl. Acad. Sci. USA 92, 9363-9367.

Erickson, S., Sangfelt, O., Heyman, M., Castro, J., Einhorn, S. and D, G., 1998. Involvement of the Ink4 proteins p16 and p15 in T-lymphocyte senescence. Oncogene 17, 595-602.

Forsyth, N.R., Elder, F.F., Shay, J.W. and Wright, W.E., 2005. Lagomorphs (rabbits, pikas and hares) do not use telomere-directed replicative aging in vitro. Mech. Ageing Dev. 126, 685-691. 
Forsyth, N.R., Evans, A.P., Shay, J.W. and Wright, W.E., 2003. Developmental differences in the immortalization of lung fibroblasts by telomerase. Aging Cell 2, 235-243.

Hayflick, L., 1965. The limited in vitro lifetime of human diploid cell strains. Exp. Cell Res. 37, 614-636.

Hayflick, L. and Moorhead, P.S., 1961. The serial cultivation of human diploid cell strains. Exp. Cell Res. 25, 585-621.

Herbig, U., Jobling, W.A., Chen, B.P., Chen, D.J. and Sedivy, J., 2004. Telomere shortening triggers senescence of human cells through a pathway involving ATM, p53, and p21(CIP1), but not p16(INK4a). Mol. Cell 14, 501-513.

Hofseth, L.J., Hussain, S.P. and Harris, C.C., 2004. p53: 25 years after its discovery. Trends Pharmacol. Sci. 25, 177-181.

Holst, C.R., Nuovo, G.J., Esteller, M., Chew, K., Baylin, S.B., Herman, J.G. and Tlsty, T.D., 2003. Methylation of p16(INK4a) promoters occurs in vivo in histologically normal human mammary epithelia. Cancer Res. 63, 1596-1601.

Itahana, K., Zou, Y., Itahana, Y., Martinez, J.L., Beausejour, C., Jacobs, J.J., Van Lohuizen, M., Band, V., Campisi, J. and Dimri, G.P., 2003. Control of the replicative life span of human fibroblasts by $\mathrm{p} 16$ and the polycomb protein Bmi-1. Mol. Cell. Biol. 23, 389-401.

Johnson, T.E., de Castro, E., Hegi de Castro, S., Cypser, J., Henderson, S. and Tedesco, P., 2001. Relationship between increased longevity and stress resistance as assessed through gerontogene mutations in Caenorhabditis elegans. Exp. Gerontol. 36, 1609-1617.

Krishnamurthy, J., Torrice, C., Ramsey, M.R., Kovalev, G.I., Al-Regaiey, K., Su, L. and Sharpless, N.E., 2004. Ink4a/Arf expression is a biomarker of aging. J. Clin. Invest. 114, 1299-1307.

Krtolica, A., Parrinello, S., Lockett, S., Desprez, P. and Campisi, J., 2001. Senescent fibroblasts promote epithelial cell growth and tumorigenesis: A link between cancer and aging. Proc. Natl. Acad. Sci. USA 98, 12072-12077.

Lin, A.W., Barradas, M., Stone, J.C., van Aelst, L., Serrano, M. and Lowe, S.W., 1998. Premature senescence involving p53 and p16 is activated in response to constitutive MEK/MAPK mitogenic signaling. Genes Dev. 12, 3008-3019.

Lithgow, G.J. and Walker, G.A., 2002. Stress resistance as a determinate of C. elegans lifespan. Mech. Ageing Dev. 123, 765-771.

Martin, G.M., 1993. Clonal attenuation: causes and consequences. J. Gerontol. 48, 171172.

Martin, G.M., Sprague, C.A. and Epstein, C.J., 1970. Replicative life span of cultivated human cells: effect of donor's age, tissue and genotype. Lab. Invest. 23, 86-92.

Mawal-Dewan, M., Frisoni, L., Cristofalo, V.J. and Sell, C., 2003. Extension of replicative lifespan in WI-38 human fibroblasts by dexamethasone treatment is accompanied by suppression of p21 Waf1/Cip1/Sdi1 levels. Exp. Cell Res. 285, 91-98.

Michaloglou, C., Vredeveld, L.C.W., Soengas, M.S., Denoyelle, C., van der Horst, C.M.A.M., Majoor, D.M., Shay, J.W., Mooi, W.J. and Peeper, D.S., 2005. $\mathrm{BRAF}^{\mathrm{E} 600}$-associated senescence-like cell cycle arrest of human nevi. Nature 436, 720-724.

Ohtani, N., Yamakoshi, K., Takahashi, A. and Hara, E., 2004. The p16INK4a-RB pathway: molecular link between cellular senescence and tumor suppression. J. Med. Invest. 51, 146-153.

Packer, L. and Fuehr, K., 1977. Low oxygen concentration extends the lifespan of cultured human diploid cells. Nature 267, 423-425. 
Parrinello, S., Coppe, J.P., Krtolica, A. and Campisi, J., 2005. Stromal-epithelial interactions in aging and cancer: senescent fibroblasts alter epithelial cell differentiation. J. Cell Sci. 118, 485-496.

Parrinello, S., Samper, E., Goldstein, J., Krtolica, A., Melov, S. and Campisi, J., 2003. Oxygen sensitivity severely limits the replicative life span of murine cells. Nature Cell Biol. 5, 741-747.

Prowse, K.R. and Greider, C.W., 1995. Developmental and tissue-specific regulation of mouse telomerase and telomere length. Proc. Natl. Acad. Sci. USA 92, 48184822.

Ramirez, R.D., Morales, C.P., Herbert, B.S., Rohde, J.M., Passons, C., Shay, J.W. and Wright, W.E., 2001. Putative telomere-independent mechanisms of replicative aging reflect inadequate growth conditions. Genes Dev. 15, 398-403.

Reznikoff, C.A., Yeager, T.R., Belair, C.D., Savelieva, E., Puthenveettil, J.A. and Stadler, W.M., 1996. Elevated p16 at senescence and loss of p16 at immortalization in human papillomavirus $16 \mathrm{E} 6$, but not E7, transformed human uroepithelial cells. Cancer Res. 56, 2886-2890.

Rheinwald, J.G., Hahn, W.C., Ramsey, M.R., Wu, J.Y., Guo, Z., Tsao, H., De Luca, M., Catricala, C. and O'Toole, K.M., 2002. A two-stage, p16(INK4A)- and p53dependent keratinocyte senescence mechanism that limits replicative potential independent of telomere status. Molec. Cell. Biol. 22, 5157-5172.

Rodier, F., Kim, S.H., Nijjar, T., Yaswen, P. and Campisi, J., 2005. Cancer and aging: the importance of telomeres in genome maintenance. Int. J. Biochem. Cell Biol. 37, 977-990.

Rohme, D., 1981. Evidence for a relationship between longevity of mammalian species and life spans of normal fibroblasts in vitro and erythrocytes in vivo. Proc. Natl. Acad. Sci. USA 78, 5009-5013.

Sager, R., 1991. Senescence as a mode of tumor suppression. Environ. Health Persp. 93, 59-62.

Saito, H., Hammond, A.T. and Moses, R.E., 1995. The effect of oxygen tension on the in vitro life span of human diploid fibroblasts and their transformed derivatives. Exp. Cell Res. 217, 272-279.

Sasaki, M., Ikeda, H., Haga, H., Manabe, T. and Nakanuma, Y., 2005. Frequent cellular senescence in small bile ducts in primary biliary cirrhosis: a possible role in bile duct loss. J. Patholog. 205, 451-459.

Schmitt, C.A., Fridman, J.S., Yang, M., Lee, S., Baranov, E., Hoffman, R.M. and Lowe, S.W., 2002. A senescence program controlled by $p 53$ and p16INK4a contributes to the outcome of cancer therapy. Cell 109, 335-346.

Schneider, E.L. and Mitsui, Y., 1976. The relationship between in vitro cellular aging and in vivo human aging. Proc. Natl. Acad. Sci. USA 73, 3584-3588.

Shapiro, G.I., Edwards, C.D., Ewen, M.E. and Rollins, B.J., 1998. p16INK4A participates in a $\mathrm{G} 1$ arrest checkpoint in response to DNA damage. Mol. Cell. Biol. 18, 378387.

Sherr, C.J. and DePinho, R.A., 2000. Cellular senescence: Mitotic clock or culture shock? Cell 102, 407-410.

Speakman, J.R., 2005. Correlations between physiology and lifespan - two widely ignored problems with comparative studies. Aging Cell 4, 167-175.

Steinert, S., White, D.M., Zou, Y., Shay, J.W. and Wright, W.E., 2002. Telomere biology and cellular aging in nonhuman primate cells. Exp. Cell Res. 272, 146-152.

Wright, W.E., Piatyszek, M.A., Rainey, W.E., Byrd, W. and Shay, J.W., 1996. Telomerase activity in human germline and embryonic tissues and cells. Dev. Genet. 18, 173-179. 
Wright, W.E. and Shay, J.W., 2002. Historical claims and current interpretations of replicative aging. Nature Biotechnol. 20, 682-688.

Yap, D.B., Hsieh, J.K., Chan, F.S. and Lu, X., 1999. mdm2: a bridge over the two tumour suppressors, p53 and Rb. Oncogene 18, 7681-7689.

Zindy, F., Quelle, D.E., Roussel, M.F. and Sherr, C.J., 1997. Expression of the p16INK4a tumor suppressor versus other INK4 family members during mouse development and aging. Oncogene 15, 203-211. 